\title{
Analytical Methods for Standardization of Ayurvedic Asavas and Aristas; A Review
}

\author{
C. DAS, G. GHOSH, A. BOSE${ }^{1}$ AND D. DAS*
}

Department of Pharmacognosy, ${ }^{1}$ Department of Pharmaceutical Analysis and Quality Assurance, School of Pharmaceutical Sciences, Siksha 'O' Anusandhan, Deemed to be University, Khandagiri Square, Bhubaneswar-751 003, India

Das et al.: Analytical Methods of Standardization of Asava and Arista

\begin{abstract}
Plants serve as a rich source of bioactive molecules, which are used to treat various diseases in Ayurveda. Medicinal plant materials are formulated into valuable Ayurvedic medicines by application of modern scientific techniques, where standardization plays a pivotal role for authentication. Standardization confirms the identity, quality and purity of drugs. World Health Organization has set up suitable specific standardization parameters to evaluate the crude drugs and their finished products. These include various evaluation techniques such as pharmacognostical, physico-chemical, phytochemical, analytical, biological and biotechnological. Nowadays, application of several modern analytical techniques have become inevitable for evaluating the polyherbal Ayurvedic formulations to ensure quality, safety and efficacy. Various spectroscopic and chromatographic methods applicable for this purpose are ultra-violet spectroscopy, Fourier-transform infrared spectroscopy, nuclear magnetic resonance spectroscopy, thin-layer chromatography, high performance thin layer chromatography, high performance liquid chromatography, gas chromatography, mass spectroscopy and hyphenated techniques such as gas chromatography-mass spectroscopy, liquid chromatography-mass spectroscopy, liquid chromatography-nuclear magnetic resonance spectroscopy. Out of several formulations available in Ayurveda, asavas and aristas are considered as unique dosage forms due to their indefinite shelf life. Standardization of different asava-arista formulations using various analytical techniques are vividly discussed in this review.
\end{abstract}

Key words: Ayurveda, asava, arista, standardization, analytical methods

Medicinal plants are known to contain various bioactive phytoconstituents, which are used for prevention and mitigation of various ailments all over the world. About $80 \%$ of the world population depends upon herbal preparation for their primary health care ${ }^{[1]}$. India is considered as rich source of a good number of medicinal plants and thus called as medicinal garden of the world. Medicinal plants are best adopted by rural and urban community in India due to their nontoxic nature, less side effects and low price. Nowadays, there has been an increase in demand for these plantbased products in developed countries as well ${ }^{[2]}$. Plant, mineral and animal-based natural drugs are the main sources, which contribute the bioactive components for preparation of various Ayurvedic formulations. The ancient books such as Rigveda, Atharvaveda, Charaka Samhita, Sushruta Samhita, Astanga Hridaya and Sangraha, describe various formulations and their uses against different diseases. Serious adverse toxic effects of synthetic drugs have shifted attention of modern

*Address for correspondence

E-mail: debajyotidas@soauniversity.ac.in

May-June 2019 civilization more towards the Ayurvedic formulations for safer remedies. However, there is a lack of quality in herbal preparations due to geographical variation, confusion with different regional names, adulteration and substitution and absence of proper standardization procedures for evaluation of raw materials and finished products. Therefore, at present standardization of crude drugs as well as their formulations by implementation of quality control parameters has become highly essential ${ }^{[3]}$. It is observed that development of suitable standard procedures for authentication of complex herbal formulations is not an easy task. The traditional methods of drug evaluation are not sufficient to establish the quality aspects of complex polyherbal

This is an open access article distributed under the terms of the Creative Commons Attribution-NonCommercial-ShareAlike 3.0 License, which allows others to remix, tweak, and build upon the work non-commercially, as long as the author is credited and the new creations are licensed under the identical terms

Accepted 02 March 2019

Revised 27 May 2018

Received 23 March 2017

Indian J Pharm Sci 2019;81(3):396-405 
Ayurvedic preparations. However, World Health Organization has framed certain standardization guidelines for evaluation of the crude drugs and their finished products, which include determination of their macro and microscopical characters, physico-chemical characters, presence of heavy metals, microbial limit, analytical parameters for qualitative and quantitative study of biomarkers, toxicity and biological study, DNA finger printing ${ }^{[4]}$. Asavaristas are such Ayurvedic selfgenerated alcoholic formulations, which are prepared by fermentation of an infusion or juice or decoction of drug ingredients with the addition of sugar and Dhataki pushpa (Woodfordia fruticosa) as a fermenter ${ }^{[5]}$. In this review, a discussion on the standardization of various marketed and in-house asvarista formulations by different analytical methods is presented.

\section{STANDARDIZATION OF ASAVA AND ARISTA FORMULATION}

Asavas and aristas are alcoholic preparations, prepared either by soaking the powdered drugs or the decoction of a drug, in a solution of jaggery along with a fermenter for a specified period of time, during which it undergoes fermentation to produce alcohol. These self-generated alcohols facilitate the extraction of active principles present in the drug and also serve as a preservative ${ }^{[6]}$.

Various methods applied for standardization of herbal drugs are depicted in fig. 1. Due to complexity of most Ayurvedic formulations, use of only conventional methods for standardization are not adequate for their evaluation. The Ayurvedic Pharmacopoeia of India and Pharmacopoeial standards for Ayurvedic formulations mention only the study of physico-chemical parameters and thin-layer chromatography of raw materials and formulations, which are not sufficient for proper standardization in present $\operatorname{era}^{[7,8]}$.

Therefore, modern analytical methods such as high performance thin layer chromatography (HPTLC), high performance liquid chromatography (HPLC), gas chromatography (GC) and hyphenated techniques such as liquid chromatography-mass spectroscopy (LC-MS), liquid chromatography-nuclear magnetic resonance spectroscopy (LC-NMR) and gas chromatography-mass spectroscopy (GC-MS) are applied to ascertain the quality of herbal products. Fingerprints obtained from HPTLC, HPLC are used as important tools for identification of marker compounds in the phytoconstituents and for quality control development of herbal formulations. Development and application of analytical techniques help in rapid analysis of herbal formulation in industry and assist in maintaining the therapeutic efficacy and safety of Ayurvedic preparations ${ }^{[0]}$.

Thin layer chromatography (TLC) is a common fingerprinting technique used to identify the phytoconstituents present in the drugs and thus, helps in differentiation of various plant species $^{[10-12]}$, simultaneously HPTLC is an important modern analytical method, where low or moderate polar compounds can be analysed. Pharmaceutical industries widely use this technique for method development, identification and detection of adulterants and substituents in the Ayurvedic formulations ${ }^{[13]}$. Preparative and analytical HPLC methods are used for isolation, purification and quantification of phytoconstituents in the herbal formulation ${ }^{[14]}$. Better resolution, sensitivity and rapid analysis are the important parameters considered in HPLC analysis ${ }^{[15]}$. The combination of HPLC and MS is currently the most powerful technique for the quality control of Chinese herbal medicine ${ }^{[16]}$. GC is used in characterization of volatile compounds due to its powerful separation efficiency and sensitive detection ${ }^{[17]}$. Compounds present in essential oils are identified and quantified by GC-MS analysis ${ }^{[18]}$. LC-MS is another important analytical technique for determination of quality of the drug ${ }^{[19]}$. LC-NMR is used in pharmacokinetics, toxicity studies, drug metabolism and drug discovery process due to its rapidity and sensitivity of detection ${ }^{[20,21]}$. LC-NMR technique is also used to detect adulterants in Chinese herbal medicine ${ }^{[22]}$. Standardization procedures of various asavarista formulations are discussed as follows:

\section{Abhayarista:}

A comparative study of Abhayarista formulations showed that the main polyphenolic compounds of Terminalia chebula (chebulic acid and chebulinic acid) were hydrolysed to their respective monomers and the amount of chebulic acid, gallic acid and ethyl gallate were increased after fermentation when compared to the decoction, which was estimated by HPLC (Jasco PU 1580, detector UV/Vis, Jasco UV 1575) method ${ }^{[23]}$. Ethanol content of four marketed Abhayarishta preparations were determined by GC method (Chemito GC 7610, Carbowax $20 \mathrm{M})^{[24]}$. In another study the ethanol content was determined using redox titration and $\mathrm{GC}$ method (Chemito GC 7610, Carbowax 20 M). Gallic acid, the major active constituent of the Terminalia chebula, was quantified 


\section{Methods of evaluation of asava $\&$ arista formulation}

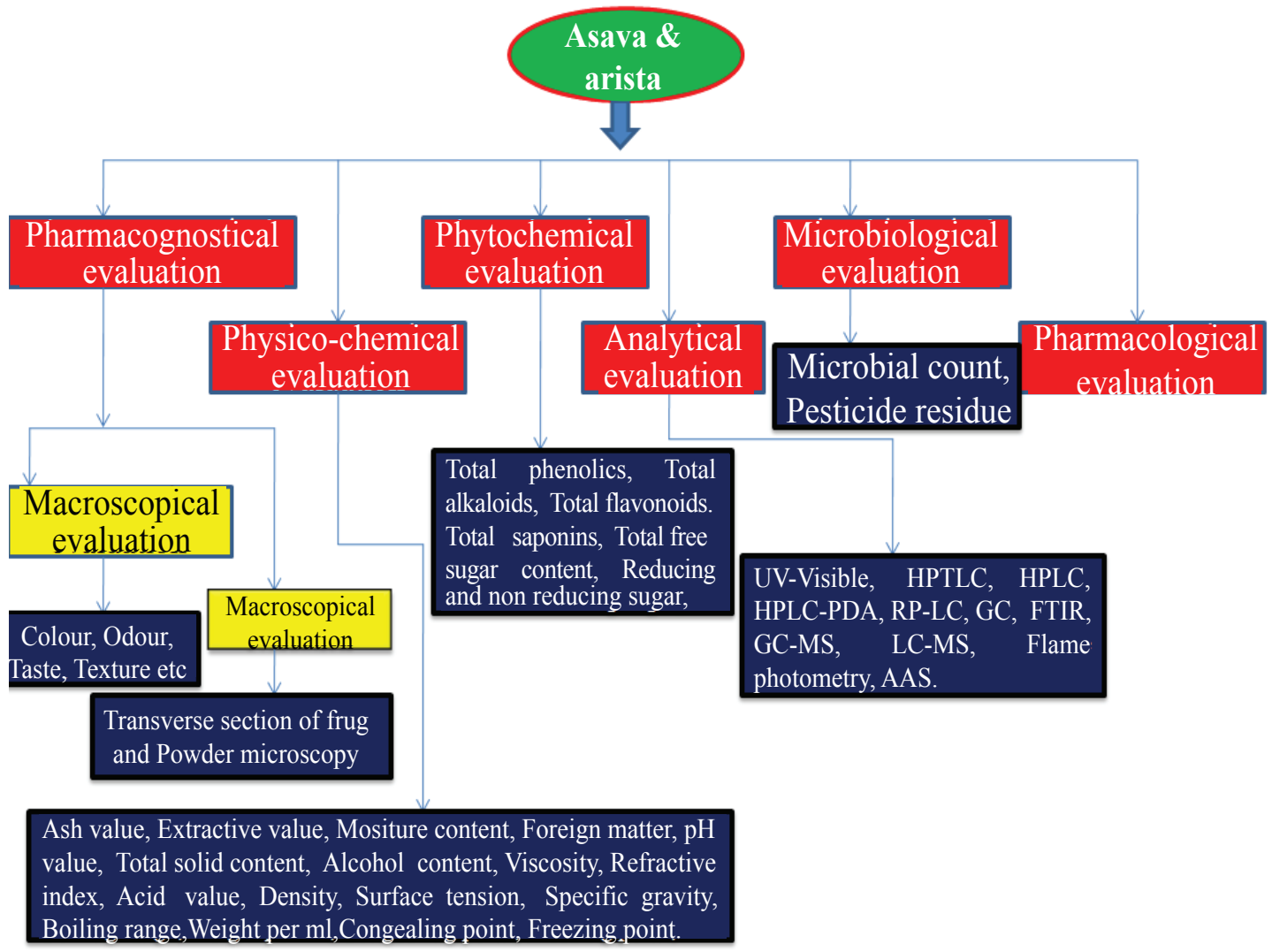

Fig. 1: Methods of evaluation of asava and arista

by UV (Shimadzu 1800, cyclomixer, Remi) and HPLC (Waters platform ZMD 4000 system, Micromass ZMD mass spectrometer, Waters 2690 HPLC equipped with a Waters 996 diode array detector, Mass Lynx software version 3.1, Waters Corp., Milford, MA, USA) methods $^{[25]}$.

\section{Amritarista:}

Amritarista was prepared using pure and authenticated ingredients according to the Ayurvedic Formulary of India and was analysed by TLC method. It showed a single spot of yellowish-brown colour under UV light with the solvent system, n-butanol:glacial acetic acid:water (4:4:2), while chromatogram was sprayed with alcoholic $\mathrm{KOH}$ solution ${ }^{[26]}$.

In another study, HPTLC (Camag, TOSOH-CCPM system, Switzerland) method was developed in order to standardize the marketed Amritarishta formulation using luteolin and apigenin as marker compounds. Two fractions (I and II) of ethanol extract of the above formulation and standard luteolin and apigenin were applied on HPTLC plate using tolune:ethyl acetate:glacial acetic acid $(5: 4: 1)$ as the mobile phase. It was observed that $\mathrm{R}_{\mathrm{f}}$ values of both luteolin (0.64) and apigenin (0.81) were found comparable in the sample and the reference standard ${ }^{[27]}$.

\section{Aravindasava:}

Aravindasava was prepared by traditional method and analysed by TLC. Aravindasava showed three spots having yellowish-grey, grey and violet colour and two brown spots under UV light at $365 \mathrm{~nm}$ using the solvent system, n-butanol:glacial acetic acid:water (4:4:2), while sprayed with alcoholic $\mathrm{KOH}$ solution $^{[26]}$.

\section{Arjunarista:}

Phenolic compounds such as ellagic acid, gallic acid, ethyl gallate, quercetin and kaemmpferol were identified using a reversed-phase HPLC (Shimadzu HPLC, Japan, LC-10AT pump, Shimadzu SPD-M10 A, version 6.10, Rheodyne 7725 I manual injector, CA, USA) method and presence of these marker compounds were compared between the drug decoction and finished formulation. Other constituents present in the formulation did not interfere with these marker compounds as these were present at very low concentration. The comparative study of two chromatograms (decoction and formulation) showed 
that the amounts of gallic acid and ellagic acid were increased during fermentation, which could be due to the hydrolysis of ellagitannins and gallitannins ${ }^{[28]}$. TLC of Terminalia arjuna showed the presence of ellagic acid $^{[29]}$. In another study, the amount of gallic acid was estimated by colorimetric analysis ${ }^{[30]}$. The amount of gallic acid and ellagic acid in Arjunarista-T (prepared by traditional method), Arjunarista-M (prepared by modern method) and its marketed formulation were determined using HPTLC (Camag, Desaga, Ziegel Wiesen, Germany, AS 30 Win sample applicator, Switzerland) method ${ }^{[31]}$.

\section{Ashokarista:}

The bark extract of Ashoka was standardised using TLC using catechin as the standard marker ${ }^{[32]}$. TLC studies of the marketed brands (Baidhyanath, Dabur, Zandu) and in-house preparation showed the presence of kaempferol, which was closer to the standard kaempferol ${ }^{[33]}$. Different types of phenolic compounds such as gallic acid, protocatechuic acid and rutin present in Ashokaritsa were identified by a liquid chromatograph coupled with photodiode array detector ${ }^{[34]}$. Total phenolics, total alkaloids, total flavonoids and total saponins in marketed and inhouse Ashokaritsa preparation were determined on a UV spectrophotometer (Shimadzu 1800, Cyclomixer, Remi). Total phenolic, flavonoid and alkaloid compounds were found to be more in the marketed formulation than in the in-house preparation. Whereas total saponin compounds were found to be very less in the marketed preparation as compared to the inhouse preparation. These differences in the amount of chemical constituents could be due to variations in geographical regions of raw materials and different methods of processing ${ }^{[35]}$. TLC of Ashokaritsa showed three spots with yellowish-grey, grey and violet colour in the solvent system n-butanol:glacial acetic acid:water (4:4:2) and one brown colour fluorescent spot under UV light at $365 \mathrm{~nm}$, which became red after spraying with alcoholic $\mathrm{KOH}^{[26]}$.

\section{Ashwagandharista:}

Ashwagandharista was standardised using a HPLC (Jasco PU 1580, detector UV/Vis, Jasco UV 1575) method with standard withaferin-A and withanolide-A ${ }^{[36]}$. TLC of Ashwagandha root powder showed one blackish-brown spot in the solvent system benzene:ethyl acetate $(9: 1)^{[37]}$. Ashwagandharista was standardised by FTIR (Jasco FTIR 410) and HPTLC
(Camag HPTLC, Linomat V applicator, TLC scanner 3 , Reprostar 3 with 12 bit CCD camera, WinCATS-4 software, Switzerland) methods for the estimation of biomarker withanolide-A. Heavy metals such as lead $(\mathrm{Pb})$, mercury $(\mathrm{Hg})$, cadmium $(\mathrm{Cd})$, arsenic (As) were detected by atomic absorption spectroscopy. FTIR studies of the formulation revealed the presence of functional groups similar to Ashwagandha powder and HPTLC study showed the presence of biomarker withanolide- $\mathrm{A}^{[38]}$. Ashwagandharista manufactured by three different companies was evaluated using chromatographic methods. The presence of withanolide-D was detected by HPTLC (Camag HPTLC, TLC scanner 3, WinCATS-4 software, Switzerland) in ASA-DAB (Ashwagandharista manufacture by Dabur) and ASA-BDN (Ashwagandharista manufacture by Baidyanath) but it was not clearly visible in ASA-AVP (Ashwagandharista manufacture by Arya Vaidya Pharmacy) due to overlapping of the bands ${ }^{[39]}$. TLC of Ashwagandharista showed only three spots under UV light with the solvent system n-butanol:glacial acetic acid:water $(4: 4: 2)^{[26]}$.

\section{Ayaskrti arista:}

Ayaskrti arista formulation of three different batches, manufactured by Arya Vaidya Sala, were collected for the analytical study. Gallic acid was quantitatively estimated in ethyl acetate extract of the formulation by a HPTLC (Camag HPTLC, Switzerland) method using the solvent system toluene:ethyl acetate:acetic acid:water $(3: 3: 0.8: 0.2)^{[40]}$.

\section{Balarista:}

Total phenolics, alkaloids, flavonoids and saponins content in marketed and in-house preparations of Balarista were determined on a UV spectrophotometer (Shimadzu 1800 and Cyclomixer, Remi). Total phenolic content was found to be less while the total flavonoid content was more in the in-house preparations, whereas the total alkaloid content in the in-house preparation was very less as compared to marketed formulation. Total saponin content was found to be almost double in the in-house preparation compared to that of the marketed formulations. The difference in the values of phytoconstituents might have developed due to variation in geographical localization of raw materials and different methods of processing ${ }^{[35]}$. In a separate study, toxic alcohol residue like methanol was found to be absent, which was confirmed by GC-MS (PerkinElmer Clarus 500 with Mass selective detector) 
analysis. The presence of aflatoxins and heavy metals were also found to be absent in the tested formulation ${ }^{[41]}$. TLC showed three spots under UV light at $365 \mathrm{~nm}$ with solvent system n-butanol:glacial acetic acid:water $(4: 4: 2)^{[26]}$.

\section{Brahmiarista:}

Marketed formulation of Brahmiarista was analysed by HPTLC (Camag Linomat V, TLC scanner 3, WinCATS software, version 1.3.0 Camag, Switzerland) using bacoside-A as the marker compound. The formulation did not show any peak corresponding to bacoside-A when it was run in toluene:ethyl acetate:methanol:glacial acetic acid and sprayed with $10 \%$ sulphuric acid in alcohol, which confirmed the absence of Bacopa monnieri as the main ingredient, rather it could contain some substitutes ${ }^{[22]}$.

\section{Chandanasava:}

The effect of time on fermentation and storage of Chandanasava was studied and evaluated using TLC. Chandanasava was prepared in an earthen pot according to the Ayurvedic Pharmacopoeial method and at $15 \mathrm{~d}$ interval, the pot was opened and the content was analysed. The formulation, which was stored in glass bottle after fermentation was subjected to TLC study. TLC showed no difference between the formulation obtained after $30 \mathrm{~d}$ of fermentation in an earthen pot and the product stored in glass bottle for three months ${ }^{[43]}$. HPTLC (Camag HPTLC, TLC scanner 3, WinCATS 4 software, Switzerland) chromatogram of Chandanasava showed a spot at the same location for all batches to confirm the batch-batch consistency ${ }^{[44]}$. Marketed Chandanasava formulation was subjected to GC-MS analysis (PerkinElmer Clarus 500 with mass selective detector), which showed the absence of toxic ingredients such as methanol, aflatoxins and heavy metals ${ }^{[41]}$. TLC showed three spots under UV light at $365 \mathrm{~nm}$ with solvent system n-butanol:glacial acetic acid:water (4:4:2), while sprayed with alcoholic $\mathrm{KOH}^{[26]}$.

\section{Drakshasava:}

Drakshasava was prepared and subjected to quantitative determination of phytoconstituents using UV spectroscopy (Shimadzu UV-1800 UV/Vis scanning spectrophotometer). Quantitative determination of total phenolics and tannins showed that these contents were 6.34 and $1.18 \mu / \mathrm{ml}$, respectively. Formulation did not show presence of alkaloids ${ }^{[45]}$.

\section{Dasamularista:}

In a comparative study, Dasamularista was prepared using identical size, shape and capacity of earthen pots, stainless steel vessel and porcelain jar by filling up to $1 / 2,2 / 3 \mathrm{rd}$ and $3 / 4$ th capacity of the container. TLC using solvent system butanol, acetic acid and water (63:17:10) showed five spots in different preparations. From different analytical and physico-chemical study results, it was found that pot filled up to 3/4th capacity was most suitable for fermenting Dasamularishta ${ }^{[46]}$. Presence of total phenolics, alkaloids, flavonoids and saponins in the marketed Dasamularishta and in the in-house preparation was analysed on a UV spectrophotometer (Shimadzu 1800 and Cyclomixer, Remi). Percent total phenolic content was found to be more in the in-house preparation than the marketed formulation, whereas the total flavonoid, alkaloid and saponin content was less in the in-house preparation than the marketed formulation. Variations in geographical sources of raw materials and different methods adopted for their processing might have influenced these differences ${ }^{[35]}$. TLC showed two spots under UV light with the solvent system n-butanol:glacial acetic acid:water $(4: 4: 2)$ when sprayed with alcoholic $\mathrm{KOH}^{[26]}$.

\section{Draksharista:}

HPTLC (Desaga, Ziegel Wiesen, AS 30 Win, Desaga TLC scanner CD 60, ProQuant software 1.06, Germany) method was developed for comparative quantification of quercetin and rutin in Draksharista formulations prepared using traditional, non-traditional method and also in marketed formulation. Mobile phase such as toluene:ethyl acetate:methanol:formic acid (6:3:0.2:0.4) and ethyl acetate:n-butanol:formic acid:water (10:6:2:2) were used for estimation of quercetin and rutin, respectively. Comparatively, formulation prepared by traditional method found to contain more quercetin and rutin than the formulations prepared by other methods ${ }^{[47]}$.

Pillai et al. performed HPTLC study (Camag HPTLC, Linomat V, WinCATS software version 1.4.6) profile of marketed Draksharista formulation and the raw materials used in the preparation. The alcohol extract of two marketed formulations and all raw materials were subjected to HPTLC analysis using gallic acid, catechin and resveratrol as marker compounds with solvent system toluene:ethyl acetate:formic acid (6:4:0.8), toluene:ethyl acetate:formic acid (5:6:1) and chloroform:ethyl acetate:formic acid 
(5:4:1), respectively. Results revealed that marketed Draksharista formulation contained all the components as mentioned in Ayurvedic Formulary of India and also contained the marker compounds ${ }^{[48]}$.

Validated HPTLC (Camag HPTLC, Linomat V, WinCATS software version 1.4.6) method was employed for the estimation of gallic acid, catechin and resveratrol in three batches of in-house Draksharista formulation and two marketed formulation (M1 and M2) using the same extract and solvent system as reported previously by Pillai et al. Gallic acid was found to be more in the in-house formulation (batch-3) as compared to marketed formulation. Catechin was found to be more in the in-house formulation (batch-1), while it is very less in the marketed formulation (M2). Resveratrol was also found to be more in the in-house formulation (batch-1) ${ }^{[49]}$.

Gallic acid and catechin were also quantitatively estimated by HPTLC (Desaga, Ziegel Wiesen, AS 30 Win, Desaga TLC scanner CD 60, ProQuant software version 1.06, Desaga, Germany) in Draksharista formulation prepared by traditional and modern methods; and also in the marketed formulation. It was observed that the amount of gallic acid and catechin were found to be more in the formulation prepared by traditional method ${ }^{[50]}$.

\section{Jirakadyarista:}

Two major compounds, apigenin-7-O-[galacturonide (1->4)-O-glucoside] and luteolin-4'-O-[glucoside-7O-galacturonide] of Jirakadyarista were detected by RP-HPLC (Shimadzu Co., Japan, LC-20AT pump, UV detector, Shimadzu SPD-20 A, Rheodyne 7725 I, CA, USA). During fermentation process 7-O-glucosides of luteolin and apigenin underwent hydrolysis to increase the amount of luteolin and apigenin in the preparation. It was also observed that monomeric phenolic compounds and 5-hydroxymethyl furfural were introduced into the formulation through the jaggery and other plant materials ${ }^{[51]}$.

\section{Kanakasava:}

Three brands of Kanakasava were procured from market and evaluated for ethanol content using specific gravity and GC methods (Chemito GC7610, Carbowax 20M). Results showed that ethanol content measured by both methods were comparable to each other and the values were found to be within the limit ${ }^{[52]}$. Gallic acid and ethyl gallate were quantitatively estimated in the ethanol fraction of Kanakasava by HPTLC (Camag
HPTLC, Linomat-V, TLC scanner 3, WinCATS-IV) using toluene:ethyl acetate:formic acid:methanol (3.5:3.5:0.8:0.5) as mobile phase $\mathrm{e}^{[53]}$.

\section{Kharjoorasava:}

Kharjoorasava was prepared by a traditional method using Dhataki pushpa (Woodfordia fruticosa) and Hapusha (Juniperus communis) as fermenter, which was evaluated using TLC. Results revealed close resemblance between the two formulations due to presence of similar secondary metabolites. During fermentation process the bioactive compounds were transformed in the formulation medium due to very slow progress in chemical reaction ${ }^{[54]}$.

\section{Kumaryasava:}

Alcohol content of Kumaryasava was determined using both specific gravity as well as GC (Chemito GC7610 Carbowax 20M) method. The result showed gradual reduction in ethanol content on storage of Kumaryasava in different containers, which may be due to vaporization on opening of the container. Therefore, asava and arista preparations have to be consumed within a shorter period of time or the formulation can be prepared in smaller volume. Total phenolic content was found to be $0.1 \%{ }^{[55]}$. According to Dash et al. ${ }^{[56]}$ the limit of total phenolic compound should not be less than $0.06 \% \mathrm{w} / \mathrm{v}$.

In another study, Kumaryasava was subjected to UV (Shimadzu Pharma spec UV-1700) and FTIR (Jasco FTIR 410) spectroscopic analysis. Aloin was isolated from different fraction of Kumariasava and used as marker for standardization by HPTLC (Camag, Linomat IV, Camag scanner 3, Switzerland) and HPLC (TOSOH-CCPM) instrumental methods. Kumaryasava was fractionated with petroleum ether, benzene, chloroform and ethyl acetate. Chloroform fraction showed five spots, which confirmed presence of five components, out of which three components were separated by preparative TLC. Fraction III, IV and $\mathrm{V}$ were found to be flavonol, isoflavones and anthraquinone, respectively. UV and IR spectra of fraction $\mathrm{V}$ produced the characteristic peaks indicating the presence of quinones. UV, IR and HPTLC fingerprints of fractions III-V could be used for routine standardization of Kumaryasava. Fraction $\mathrm{V}$ was subjected to HPLC analysis, which gave two peaks. Aloin, an anthraquinone glycoside, whose presence was confirmed by modified Borntrager test, TLC and HPLC analysis in fraction V. Both fraction 
$\mathrm{V}$ and standard marker aloin were also well compared by TLC, HPTLC and HPLC analysis, confirming the presence of aloin in Kumaryasava preparation. This could be a simple, accurate and routine method for analysis of Kumaryasava ${ }^{[57]}$.

\section{Kutajarista :}

Kutajarista was standardized by HPTLC (Camag, Linomat IV, model 3 scanner, Cats integration software, version 4.03) employing a solvent system of ethyl acetate, n-hexane and triethyl amine (70:24:6), HPLC (Water HPLC system equipped with model 510-HPLC pump, 410 RI detector, Milford, MA, USA) with methanol and water (95:5) and HPLC-MS (Waters HPLC-MS system equipped with model 2525 pump, ZQ detector) with acetonitrile and water (95:5) using conessine as the biomarker. HPTLC chromatogram of alkaloidal fraction of Kutajarista showed three well resolved spots. The spot having $\mathrm{R}_{f}$ value 0.40 matched with standard conessine after spraying with Dragendorff's reagent. The presence of conessine was confirmed in alkaloidal fraction by HPLC-MS as well. The peak of standard conessine appeared at the retention time of $12.5 \mathrm{~min}$ also appeared in extract and exhibit similar mass fragmentation. HPLC analysis of alkaloidal fraction of formulation gave a single major peak with retention time of $4.17 \mathrm{~min}$, which matched with HPLC analysis of standard conessine ${ }^{[58]}$. Microbial presence of Kutajarista at initial stage of fermentation was studied by culture independent 16SrRNA gene clone library approach. Gallic acid was recovered on d 0, ellagic acid and gallic acid on d 8 and gallolyl derivatives and ellagic acids on d 30 of fermentation, which were determined by HPLC-MS analysis (Waters HPLC-MS system equipped with model 2525 pump and ZQ detector ${ }^{[59]}$. TLC showed two spots under UV with solvent system n-butanol:glacial acetic acid:water (4:4:2) when sprayed with alcoholic $\mathrm{KOH}^{[26]}$.

The role of different types of containers and methods of preparation in Kutajarista was studied. Kutajarista was prepared by two methods, traditionally using Dhatakipuspa as fermenter and non-traditionally using yeast as fermenter, in different containers made up of mud, wood, stainless steel and plastic. Fermentation was started on d 2 in formulation containing yeast as fermenter and on d 5 in formulation containing Dhataki puspa as fermenter. Qualitative phytochemical test of formulation showed the presence of steroids, triterpenoids, proteins, tannins and alkaloids.
Quantitative determination by UV (Shimadzu UV$1800 \mathrm{UV} /$ Vis scanning spectrophotometer) showed the presence of alkaloids and tannins in highest percentage in stainless steel and plastic container for both samples prepared by traditional and non-traditional methods ${ }^{[60]}$.

\section{Lohasava:}

Lohasava was prepared according to the Ayurvedic Formulary of India and analysed by TLC. TLC study showed two spots; violet and grey under UV light using solvent system n-butanol:glacial acetic acid:water (4:4:2) when sprayed with alcoholic $\mathrm{KOH}^{[26]}$. Ethanol content of Lohasava was determined by GC (PerkinElmer GC, Clarus 500). Analysis of heavy metal was carried out on a PerkinElmer Optical Emission Spectrometer, Optima 2100DV. Pb and $\mathrm{Hg}$ were found to be absent, whereas $\mathrm{As}$ and $\mathrm{Cd}$ were present within specified limit of World Health Organisation (WHO). Gallic acid was quantitatively estimated in ethyl acetate extract of Lohasava using toluene:ethyl acetate:formic acid (10:7:1) as mobile phase by HPTLC (Camag Linomat IV, Camag scanner 3, software WinCATS 1.4.2) ${ }^{[61]}$.

\section{Mustakarista:}

Four different brands of marketed Mustakarista formulations were evaluated by GC (Chemito GC7610 Carbowax 20M) method for the quantification of alcohol content. Specific gravity and results showed gradual reduction of self-generated ethanol content on storage, which may be due to evaporation on repeated opening of the container. GC method provided accurate and precise result as compared to the specific gravity method. Variation in alcohol content was observed with different containers used in the manufacturing process. Total phenolic content was found to be 0.09 and $0.08 \%$ for two marketed formulations of Mustakarista $^{[55]}$.

\section{Saraswataristam:}

FTIR spectrum of Saraswataristam formulation showed number of peaks at $400-4000 \mathrm{~cm}^{-1}$. The broad peak was observed at 3446 and $3442 \mathrm{~cm}^{-1}$ due to presence of $\mathrm{OH}$ and functional group of other ingredients in the formulation. Similar peak was observed in Centella powder, which was the main ingredient of the formulation. HPTLC (Camag HPTLC, Linomat V applicator, TLC scanner 3, Reprostar 3 with 12 bit CCD camera, WinCATS software, Switzerland) analysis of formulation showed a peak of asiaticoside ${ }^{[62]}$. 


\section{Vidangarista:}

HPTLC (Camag, Linomat V, TLC scanner 3, WinCATS software 1.4.4.6337, Switzerland) method was developed for the quantification of biomarkers gallic acid and conessine in the Vidangarista formulation ${ }^{[63]}$. It is a polyherbal formulation mentioned in Ayurvedic Formulary of India and used as an anthelmintic.

In India Ayurvedic drug industry is growing at a rapid pace and more herbal products are released into the market. The safety and efficacy of these formulations need to be ensured through application of proper standardization protocols. Traditional methods of standardization are found to be insufficient to validate these formulations, hence, modern advanced techniques play vital role. Indian Ayurvedic formulations could be well accepted by all developed nations world-wide if these are manufactured using standard procedures and standardized using sophisticated modern analytical techniques. Fingerprint profile obtained by various chromatographic techniques play an important role for the standardization of Ayurvedic formulations. It is essential to develop advanced hyphenated techniques to serve as rapid and specific tools for herbal drug standardization. The combination of qualitative fingerprint and quantitative multicomponent analysis act as a novel and rational method in the quality control of Ayurvedic formulations. From this review it could be concluded that great scope existed to develop analytical methods to authenticate majority of asava-arista formulations. The standardization protocols using hyphenated techniques such as GCMS, LC-MS, LC-NMR, could be developed and employed for evaluation of multidrug asava-arista formulations where miniscule amount of marker compounds are available. Modern analytical methods of standardization are yet to be developed for most of the other Ayurvedic formulations.

\section{Acknowledgement:}

The authors thank the Dean, School of Pharmaceutical Sciences, Siksha 'O' Anusandhan Deemed to be University, Bhubaneswar, Odisha for providing adequate support to carry out the research work.

\section{REFERENCES}

1. Kamboj VP. Herbal medicine. Curr Sci 2000;78:35-51.

2. Sharma A, Shanker C, Tyagi LK, Singh M, Rao CV. Herbal medicine for market potential in India: An Overview. J Plant Sci 2008;1:26-36.

3. Yadav NP, Dixit VK. Recent approaches in herbal drug standardization. Int J Integr Biol 2008;2:195-203.
4. Rasheed A, SatyanarayanaKV, Gulabi PS, Sindhura M, Shama SN. Standardization: Accessing key for herbal drug safety assurance. J Pharm Res 2011;4:1322-5.

5. Mishra AK, Gupta A, Gupta V, Sannd R, Bansal P. Asava and Aristha: An Ayurvedic Medicine-An Overview. Int J Pharm Biol Arch 2010;1:24-30.

6. Anonymous. The Ayurvedic Formulary of India, Government of India. Part-I, 2nd ed. New Delhi: Ministry of Health and Family Welfare, Department of Indian system of medicine and Homoeopathy; 2003.

7. Anonymous. The Ayurvedic Pharmacopoeia of India. Part-II, Volume-II, 1st ed. New Delhi: Government of India Ministry of Health and Family Welfare, Department of Ayurveda, Yoga \& Naturopathy, Unani, Siddha and Homeopathy (Ayush); 2010.

8. Anonymous, Pharmacopoeial Standards for Ayurvedic Formulations. Revised edition. New Delhi: Central Council for Research in Ayurveda and Siddha, Ministry of Health and Family Welfare, Goverment of India; 1987-2000.

9. Liang YZ, Xie P, Chan K. Quality control of herbal medicines. J Chromatogr B Analyt Technol Biomed Life Sci 2004;812:5370.

10. Xie $\mathrm{P}$, Chen $\mathrm{S}$, Liang $\mathrm{YZ}$, Wang $\mathrm{X}$, Tian $\mathrm{R}$, Upton $\mathrm{R}$. Chromatographic fingerprint analysis - a rational approach for quality assessment of traditional Chinese herbal medicine. J Chromatogr A 2006;1112:171-80.

11. Apers S, Naessens T, Pieters L, Vlietinck A. Densitometric thin-layer chromatographic determination of aescin in a herbal medicinal product containing Aesculus and Vitis dry extracts. J Chromatogr A 2006;1112:165-70.

12. Marchand E, Atemnkeng MA, Vanermen S, PlaizierVercammen J. Development and validation of a simple thin layer chromatographic method for the analysis of artemisinin in Artemisia annua L. plant extracts. Biomed Chromatogr 2007;22:454-9.

13. Kumar A, Lakshman K, Jayaveera KN, Tripathi SNM, Satish KV. Estimation of gallic acid, Rutin, and Quercetin in Terminalia chebula by HPTLC. Jordan J Pharm Sci 2010;3:63-7.

14. Faghihi J, Jiang X, Vierling R, Goldman S, Sharfstein S, Sarver J, et al. Reproducibility of the high-performance liquid chromatographic fingerprints obtained from two soybean cultivars and a selected progeny. J Chromatogr A 2001;915:6174.

15. Rao UB, Anna NP. Stability- indicating HPLC method for the determination of efavirenz in bulk drug and in pharmaceutical dosage form. Afr J Pharm Pharmacol 2009;3:643-50.

16. Singh DP, Govindarajan R, Rawat AK. High-performance liquid chromatography as a tool for the chemical standardization of Triphala an Ayurvedic formulation. Phytochem Anal 2007;19:164-8.

17. Bombarda I, Dupuy N, Da JP, Gaydou EM. Comparative chemometric analyses of geographic origins and compositions of lavandin var. Grosso essential oils by mid infrared spectroscopy and gas chromatography. Anal Chim Acta 2008;613:31-9.

18. Binit D K, Sunil K, Nayak C, Mehta BK. Gas chromatography mass spectroscopy (GC-MS) analysis of the hexane and benzene extracts of the Piper beetle from India. J Med Plants Res 2010;4:2252-5. 
19. Ip SP, Zhao M, Xian Y, Chen M, Zong Y, Tjong YW, et al. Quality assurance for Chinese herbal formulae: Standardization of IBS-20, a 20- herb preparation. Chin Med 2010;5:8-9.

20. Dachtler M, Frans HM, De Put V, Frans V. LC-NMR-MS characterization of sesame oil extracts and assessment of their antioxidant activity. Eur J Lipid SciTechnol 2003;105:488-96.

21. Pasch H, Heinz LC, Macko T, Hiller W. High-temperature gradient HPLC and LC-NMR for the analysis of complex polyolefins. Pure Appl Chem 2008;80:1747-62.

22. Kestling JR, Haung J, Sorensen D. Identification of adulterants in a Chinese herbal medicine by LC-HRMS and LC-MS SPE/ NMR and comparative in vivo study with standards in a hypertensive rat model. J Pharm Biomed Anal 2010;51:70511.

23. Lal UR, Tripathi SM, Jachak SM, Bhutani KK, Singh IP. Chemical changes during fermentation of Abhayarishta and its standardization by HPLC-DAD. Nat Prod Commun 2010;5:575-9.

24. Wadher SJ, Puranik M, Yeole PG, Lokhande CS. Determination of ethanol in Abhayarishta by gas chromatodraphy. Indian J Pharm Sci 2007;69:152-4.

25. Kasture VS, Mutha SS, Gosavi SA, Bhalke RD, Pawar SS. Standardization of Abhyarishta as per WHO Guidelines. World J Pharm Pharm Sci 2013;3:510-8.

26. Shaila D, Santosh MK, Rao IS. Standardization of selected Asava and Aristas. Asian J Chem 2003;15:884-90.

27. Wadkar KA, Kondawar MS, Lokapure SG. Standardization of marketed Amritarishta- A herbal formulation. Int J Pharmacogn 2016; 3(9):392-9.

28. Singh IP, Lal UR, Tripathi SM, Jachak SM, Bhutani KK. HPLC Analysis and Standardization of Arjunarishta - An Ayurvedic Cardioprotective Formulation. Sci Pharm 2009;77:605-16.

29. Singh H, Mishra SK, Pande DM. Standardization of Arjunarishta formulation by TLC method. Int J Pharm Sci Rev Res 2010;2:25-8.

30. Ragini H, Amita P, Jain AK. An approach to standardize Arjunarishta: a well-known Ayurvedic formulation using UV and Colorimetric method. J Med Pharm Allied Sci 2012;1:7784.

31. Tiwari P, Patel RK. Quantification of gallic acid and ellagic acid in Arjunarishta by validated HPTLC Densitometry. Int J Pharm Sci Res 2012;3:2215-23.

32. Singh H, Parihar SS, Mishra SK, Rathore A. Standardization of Ashokarista formulation by TLC method. Int J Pharm Tech Res 2010;2:1427-30.

33. Kumar T, Larokar YK, Jain V. Standardization of different marketed brands of Ashokarishta: An Ayurvedic formulation. J Sci Inno Res 2013;2:993-8.

34. Govindarajan R, Singh DP, Rawat AKS. Validated RP-LC Method for standardization of Ashokarishta: A polyherbal formulation. Chromatographia 2008;68:873-6.

35. Vador N, Vador B, Hole R. Simple spectrophotometric methods for standardizing Ayurvedic formulation. Indian $\mathrm{J}$ Pharm Sci 2012;74:161-3.

36. Bhondave PD, Devarshi PP, Mahadik KR, Harsulkar AM. 'Ashvagandharishta' prepared using yeast consortium from Woodfordia fruticosa flowers exhibit hepato protective effect on $\mathrm{CCl}_{4}$ induced liver damage in Wistar rats. J Ethnopharmacol 2014;151:183-90.

37. Kushwaha R, Karanjekar S. Standardization of Ashwagandharishta formulation by TLC method. Int J ChemTech Res 2011;3:1033-6.
38. Rasheed A, Roja C, Reddy GAK, Reddy BS. Formulation, standardization and pharmacological evaluation of a poly herbal traditional remedy -Ashwagandharishtam. Orient Pharm Exp Med 2012;12:51-8.

39. Singh M, Kaur N, Paul AT. Physicochemical standardization, HPTLC profiling, and biological evaluation of Asvagandhadyarista: A comparative study of three famous commercial brands. Anc Sci Life 2014;33:165-71.

40. Sankar K, Bhutani KK. Standardization of a polyherbal Ayurvedic formulation: Ayaskrti. Indian $\mathrm{J}$ Tradit know 2011;10:589-93.

41. Sekar S, Vinothkanna A, Mariappan S. Tracking the organoleptic and biochemical changes in the Ayurvedic polyherbal and native fermented traditional medicines: Balarishta and Chandanasava. Int J Pharm Pharm Sci 2014;6:521-6.

42. Tatke P, Jirge S, Gabhe SY. Marker based standardisation of plant based formulations containing Brahmi using bacoside a by HPTLC. Int J Pharm Pharm Sci 2014;6:202-7.

43. Alam M, Rukmani B, Shanmughadasan KK, Purushothaman KK. Effect of time on the Fermentation and storage of Candanasava. Anc Sci Life 1984;4:51-5.

44. Sankar K, Singh A. Standardization of polyherbalayurvedic formulation: Chandanasava. Int J Res Ayu Pharm 2011;2:665-9.

45. Sailor G, Seth A, Parmar K, Patel M, Shrirang P. Standardization of marketed Drakshasava - A polyherbal Ayurvedic product. Int J Pharm Sci 2013;4:363-70.

46. Alam M, Dasan KKS, Joy S, Purushothaman KK. Comparative and fermentation standardisation Studies on Dasamularishta. Anc Sci Life 1988;8:68-70.

47. Tiwari P, Patel RK. Development and validation of HPTLC method for quantification of quercetin and rutin in Draksharishta. Asian J Pharm Sci Res 2012;2:7-18.

48. Pillai D, Pandita N. Determination of Quality Standards for Draksharishta, a Polyherbal Ayurvedic Formulation. Indian J Pharm Sci 2016;78(1):129-35.

49. Pillai D, Pandita N. Validated high performance thin layer chromatography method for the quantification of bioactive marker compounds in Draksharishta, an Ayurvedic polyherbal formulation. Braz J Pharmacog 2016;26:558-63.

50. Tiwari P, Sen DJ, Patel RK. Development and Validation of HPTLC Method for Quantification of Gallic acid and Catechin from Draksharishta. Asian J Res Chem 2013;6(3):248-53.

51. Lal UR, Tripathi SM, Jachak SM, Bhutani KK, Singh IP. RP-HPLC analysis of Jirakadyarishta and chemical changes during fermentation. Nat Prod Commun 2010;5:1767-70.

52. Gharate MK, Pawar R, Kasture V, Patil R. Evaluation of quantitative parameters of Ayurvedic formulation: Kankasava. Int J Pharm Pharm Sci 2011;3:43-5.

53. Arora P,Ansari SH, Anjum V, Mathur R, Ahmad S. Investigation of anti-asthmatic potential of Kanakasava in ovalbumininduced bronchial asthma and airway inflammation in rats. J Ethnopharmacol 2017; 197:242-9.

54. Sathyajith R, Krishnamurthy MS, Shimi Ben CJ, Trimurthy SK. Pharmaceutico-chemical analysis of kharjoorasava and evaluation of its clinical efficacy in panduroga. Int J Res Aayu Pharm 2014;5:447-51.

55. Sanmuga PE, Priya ES. Determination of Ethanol Content in Ayurvedic Formulations Kumaryasava and Mustakarista by Gas Chromatography. Indian J Pharm Sci 2015;77:120-5.

56. Dash VB, Junius AM. A Handbook of Ayurveda. Kandern, Germany: Narayana Publishers; 2003. 
57. Tatke PA, Elamthuruthi AT, Shah CR, Khan TA, Gabhe SY. Standardization of marketed Kumariasava; An Ayurvedic Aloe vera product. J Pharm Biomed Anal 2005;37:937-41.

58. Garg S, Bhutani KK. Chromatographic analysis of Kutajarista-Anayurvedic polyherbal formulation. Phytochem Anal 2008;19:323-8.

59. Shouche YS, Kumar H, Pandey PK, Doiphode VV, Bhutani KK, Patole MS, et al. Microbial community structure at different fermentation stages of Kutajarista, a herbal formulation. Indian J Microbiol 2013;53:11-7.

60. Hiremath SG, Joshi DD. Role of different containers and methods on alcoholic preparations with reference to Kutajarista. Anc Sci Life 1991;10:256-63.

61. Mansuri AA, Desai SS. Systemic standardization of Lohasava-An antianemic polyherbal formulation. Indian Drugs 2017;54(09):33-7.

62. Rasheed A, Sri MT, Mohammed-Haneefa KP, ArunKumar RP, Azeem AK. Formulation, standardization and pharmacological studies of Saraswataristam: a polyhedral preparation. Pak J Pharm Sci 2014;27:1163-9.

63. Bhujbal P, Sandhya P. Chromatographic analysis of bioactive markers in Vidangarista, an Ayurvedic polyherbal formulation. J Planar Chromatogr 2012;25:42-7. 